\title{
OPEN Pulmonary surfactant inhibition of nanoparticle uptake by alveolar epithelial cells
}

\author{
M. Radiom ${ }^{1,3 \bowtie}$, M. Sarkis ${ }^{1}$, O. Brookes ${ }^{2}$, E. K. Oikonomou ${ }^{1}$, A. Baeza-Squiban ${ }^{2} \&$ \\ J.-F. Berret ${ }^{1 凶}$
}

Pulmonary surfactant forms a sub-micrometer thick fluid layer that covers the surface of alveolar lumen and inhaled nanoparticles therefore come in to contact with surfactant prior to any interaction with epithelial cells. We investigate the role of the surfactant as a protective physical barrier by modeling the interactions using silica-Curosurf-alveolar epithelial cell system in vitro. Electron microscopy displays that the vesicles are preserved in the presence of nanoparticles while nanoparticle-lipid interaction leads to formation of mixed aggregates. Fluorescence microscopy reveals that the surfactant decreases the uptake of nanoparticles by up to two orders of magnitude in two models of alveolar epithelial cells, A549 and NCl-H441, irrespective of immersed culture on glass or air-liquid interface culture on transwell. Confocal microscopy corroborates the results by showing nanoparticle-lipid colocalization interacting with the cells. Our work thus supports the idea that pulmonary surfactant plays a protective role against inhaled nanoparticles. The effect of surfactant should therefore be considered in predictive assessment of nanoparticle toxicity or drug nanocarrier uptake. Models based on the one presented in this work may be used for preclinical tests with engineered nanoparticles.

The exchange of gas in the lungs during breathing exposes the epithelium of the respiratory tract to pathogens and airborne particulate matter (PM) such as natural and engineered particles. Exposure to natural and anthropogenic PM such as crystalline silica dust, asbestos fibers, coal dust, and diesel exhaust particles has long been known to pose important health hazards, e.g. increasing the risk of lung cancer and chronic obstructive pulmonary disease (COPD). Therefore, inhalation of PM is a current global health concern ${ }^{1}$. Geographical maps of air pollution suggest a world average concentration of $25 \mu \mathrm{g} \mathrm{m}^{-3}$ of suspended $\mathrm{PM}_{2.5}$ (PM with an aerodynamic diameter $\leq 2.5 \mu \mathrm{m})^{2,3}$. This concentration is equivalent to $300 \mu \mathrm{g}$ of $\mathrm{PM}_{2.5}$ inhaled on daily basis, of which 8-50\% or 20-160 $\mu \mathrm{g}$ may enter the lungs as schematically shown in Fig. $1 \mathrm{a}^{4}$. Movement of $\mathrm{PM}_{2.5}$ to different regions of the lungs is dependent on several factors including physiological ones such as breathing patterns, and physical ones such as particle size and deposition mechanics ${ }^{4}$. Several models for estimating deposition fraction in different regions of the lungs exist, and they show that nanoparticles (aerodynamic diameter $\leq 100 \mathrm{~nm}$ ) can spread deeply in the lungs ${ }^{4}$. The deposition fraction of nanoparticles in distal lung regions, i.e. the alveolar region, is estimated to be $15-32 \%$ from IDEAL model (for oral breathing, tidal volume $=1000 \mathrm{ml}$, and frequency of breathing $\left.=15 \mathrm{~min}^{-1}\right)^{4}$. This model's estimations are reproduced in Fig. 1c. Using the above range and assuming exposure to nanoparticles alone, the lung burden of inhaled nanoparticles in the alveolar region is 3-50 $\mu \mathrm{g}$ on daily basis.

The alveolar region is composed of sponge-like clusters of pulmonary alveoli (air sacs), each of which has a diameter of about $200 \mu \mathrm{m}$, as shown schematically in Fig. 1a,b. The alveolar region presents a very large potential exposure surface, more than $70 \mathrm{~m}^{25}$. Furthermore, the alveoli are bounded by an epithelial cell layer, which rests in contact with endothelial cells of pulmonary capillaries via an extracellular matrix. The tissue is very thin, less than $2 \mu \mathrm{m}$, and is a major potential route of systemic entry of inhaled nanoparticles ${ }^{6-13}$. For example, about $20-30 \%$ of endotracheally ventilated aerosolized titanium oxide nanoparticles $(22 \mathrm{~nm})$ had translocated through the alveolar lumen within $1 \mathrm{~h}$ post-exposure ${ }^{8}$. For intratracheally instilled gold nanoparticles (bare particle diameter equal to $11 \mathrm{~nm}$, and with polyethylene glycol coating equal to $21 \mathrm{~nm}$ and $31 \mathrm{~nm}$ ), up to $3 \%$ had entered secondary organs including liver, spleen and kidneys ${ }^{14}$.

${ }^{1}$ UMR CNRS 7057, Laboratoire Matière Et Systèmes Complexes, Université de Paris, Paris, France. ${ }^{2}$ UMR CNRS 8251, Unité de Biologie Fonctionnelle et Adaptative, Université de Paris, Paris, France. ${ }^{3}$ Present address: Institute for Food, Nutrition and Health, D-HEST, ETH Zürich, Zürich, Switzerland. ${ }^{\circledR}$ email: milad.radiom@hest.ethz.ch; jean-francois.berret@u-paris.fr 
(a)
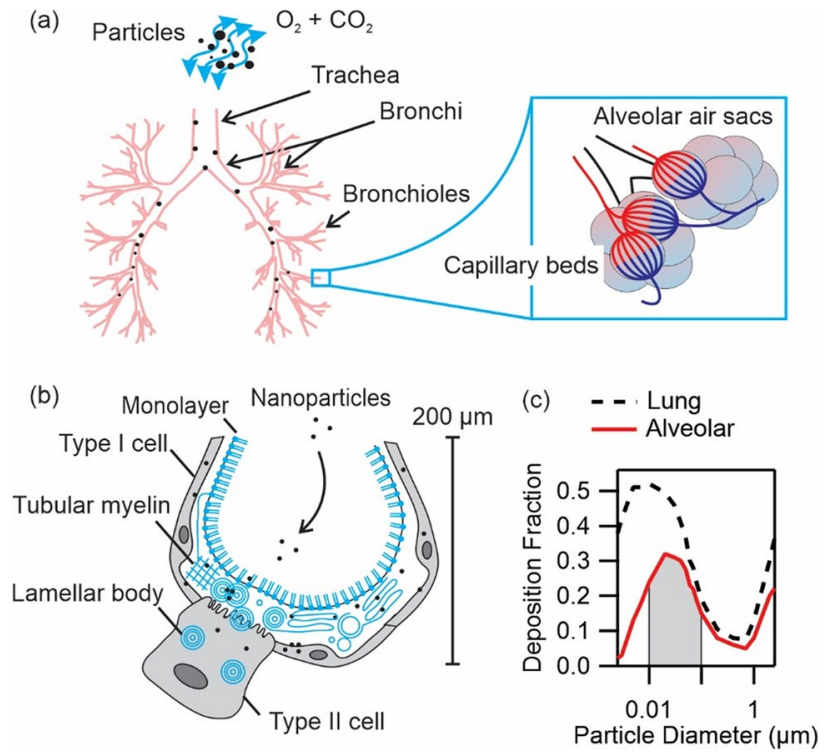

Figure 1. (a) Schematic of particles entering the lungs during respiration. Lung sections including trachea, bronchi, bronchioles and alveolar air sacs are depicted. Airway diameters decrease in the same order from $12 \mathrm{~mm}$ to $200 \mu \mathrm{m}$. Nanoparticles can diffuse deeply and enter the alveolar air sacs. (b) Alveolar epithelium is composed of type I and type II cells. Type II cells secrete surfactant to alveolar lumen which then forms surfactant monolayer at air-liquid interface, tubular myelin and lamellar body structures in the surfactant film. (c) Total lung, i.e. tracheobronchial plus alveolar, and alveolar deposition fractions reproduced from IDEAL model calculations in Ref. ${ }^{4}$. Shaded area marks the deposition fraction of nanoparticles, diameter in the range $10-100 \mathrm{~nm}$, in the alveolar region equal to $15-32 \%$.

The first barrier to nanoparticles in the alveoli is pulmonary surfactant. This fluid is secreted by type II epithelial cells and covers the epithelium with a thickness of about $0.2-0.5 \mu \mathrm{m}$ (Fig. 1b) ${ }^{15}$. The surfactant is composed of $92 \%$ lipids, out of which $78 \%$ are zwitterionic phosphatidylcholines (PC), and predominantly dipalmitoyl PC. The non-lipid fraction of surfactant primarily consists of proteins. Upon secretion, the surfactant forms a lipid monolayer at air-liquid interface, and tubular myelin and lamellar body structures in the film. Formation and stability of these structures is mediated by interactions with surfactant proteins, notably SP-A, SP-B and SP-C ${ }^{16-18}$. Surfactant proteins SP-A and SP-D are furthermore components of innate immune system and facilitate complement activation and phagocytosis ${ }^{18}$. The fate of nanoparticles in alveolar region, including translocation through the epithelial cell layer or internalization by immune cells ${ }^{6,19-23}$, depends on their interaction with the surfactant.

These observations have prompted investigations into nanoparticle-surfactant interaction and its role on cellular uptake of the nanoparticles. Reported interactions with silica, alumina and latex nanoparticles in dilute surfactant include formation of supported lipid bilayers (SLBs), internalization by lipid vesicles, and aggregate formation. These assemblies are formed spontaneously and depend on particle size, roughness, and short- and long-range interactions such as steric and electrostatic forces ${ }^{24-27}$. Other non-specific interactions leading to disintegration, reduction in size, and deformation of multivesicular structures have been observed with titanium oxide nanoparticles at in vivo surfactant concentration ${ }^{28}$. These interactions can change the biophysical properties of surfactant as recently shown in case of its flow properties ${ }^{29}$.

Subsequent investigations examined cell responses to nanoparticles mediated by interactions with surfactant. Among other studies, it was shown by us that surfactant diminishes the uptake of silica nanoparticles by murine macrophages and lung carcinoma cells ${ }^{30}$. It was also found that surfactant reduces the amount of internalized dextran nanogels used for delivery of small interfering $\mathrm{RNA}^{31,32}$. The uptake of silver nanowires was however mediated only by harvested in vitro surfactant secretions which includes proteins, while no reduction was observed in the presence of Curosurf (a surfactant substitute which lacks SP-A and SP-D) ${ }^{33}$. These differences of behavior are related with different physical and chemical properties of nanoparticles, e.g. metal vs. non-metal, spherical vs. ellipsoidal, and surfactant, e.g. containing proteins SP-A and SP-D, or devoid of them, in addition to cells with different uptake mechanisms, e.g. murine macrophages, human primary cells and cell lines, but also on relative concentration of surfactant to nanoparticles. Thereby our understanding of the fate of nanoparticles in pulmonary alveoli is not complete.

To this end, we mimic this process in vitro by exposing a monolayer of alveolar epithelial cells to a mixture of clinical surfactant substitute and nanoparticles. Our model nanoparticles are positively charged silica. Silica nanoparticles are commonly used in cosmetology products, in food as emulsifiers, in paints and as medical tools e.g. as drug-carriers, contrast agents and anti-cancer therapeutics ${ }^{34,35}$. The high level of consumption of this material has resulted in its mass production leading to a high risk of exposure by inhalation especially in occupational settings. (A list of production volume and industrial applications for silica nanoparticles is provided in Supplementary Information (S), S1). Long term exposure to crystalline silica dust is associated with 
pulmonary diseases such as silicosis, lung cancer, COPD and pulmonary tuberculosis ${ }^{34}$. In addition to silica dust, amorphous silica nanoparticles may exhibit toxicity depending on surface properties ${ }^{36}$; however, they pose an additional hazard associated with translocation through the alveolar tissue and systemic circulation leading to accumulation in secondary organs ${ }^{6-14}$. The choice of a positive surface charge is motivated by recent observations that nanoparticles with positive surface charge are more cytotoxic to macrophages as compared to neutral and negatively charged particles ${ }^{37}$. Furthermore, our group has recently shown that nanoparticles with positive surface charge interact strongly with pulmonary surfactant via electrostatic forces ${ }^{26,38}$. In a previous work, we focused our attention on SLBs that were induced on silica nanoparticles via sonication ${ }^{39}$. The current study investigates the protective role of surfactant in an attempt to mimic the in vivo exposure condition more closely. Thereby, silica nanoparticles and model surfactant Curosurf were mixed without sonication. In this case, we did not observe SLBs around nanoparticles; however, nanoparticles were found inside the mutivesicular structures and adhering to the lipid membranes. The choice of Curosurf is motivated by its approximation of the native surfactant in terms of lipid and protein compositions (S2). Curosurf is also used in the treatment of respiratory distress syndrome (RDS) in pre-term enfants. We examined two cell lines, namely A549 and NCI-H441; both are common models of pulmonay alveolar cells while the latter shows better barrier forming properties. The investigations were performed on glass and on transwell. The choice of transwell is to induce air-liquid interface (ALI) which leads to tight epithelium forming in NCI-H441 cells. We measured uptake at several surfactant to nanoparticle concentration ratios, where we found reduction by two orders of magnitude in uptake when surfactant was present. By fluorescently tagging the lipids ${ }^{40}$ and the nanoparticles, we showed their colocalization on exposure to cells. Our result thus corroborates the protective role of surfactant in reducing the number of nanoparticle-cell interactions leading possibly to a reduced nanoparticle internalization, which further manifests the protective role of surfactant in reducing systemic circulation from alveolar entry route.

\section{Material and methods}

Cell culture. Adenocarcinoma A549 and NCI-H441 were obtained from the American Type Culture Collection (ATCC, USA). NCI-H441 was cultured in RPMI-1640 supplemented with 10\% fetal bovine serum (FBS), $1 \%$ penicillin-streptomycin (PS), 1\% GlutaMAX, 1\% non-essential amino acids, $1 \%$ sodium pyruvate and $200 \mathrm{nM}$ dexamethasone in T25 flasks inside an incubator (atmosphere of $5 \% \mathrm{CO}_{2}, 37^{\circ} \mathrm{C}$ ). Dexamethasone is a glucocorticoid supplement used to promote maturation of epithelial cells and to improve their barrier properties ${ }^{41}$. A549 was cultured in DMEM supplemented with 10\% FBS and 1\% PS in T25 flasks inside an incubator $\left(5 \% \mathrm{CO}_{2}\right.$, $37^{\circ} \mathrm{C}$ ). Of note, A549 was not cultured in dexamethasone, except for the experiments on transwell and after establishment of air-liquid interface (ALI) culture, because it has been shown that dexamethasone inhibits A549 proliferation ${ }^{42}$. Both cell lines were harvested by trypsinization with Trypsin-EDTA. Sterilized glass coverslips were placed inside 6-well plates. Cells were seeded at a density of $4 \times 10^{4} \mathrm{cells} \mathrm{cm}^{-2}$ and incubated for $48 \mathrm{~h}$. Costar 12-mm Transwell $0.4-\mu \mathrm{m}$ pore polyester membrane inserts were used for ALI culture. On transwell, cells were seeded at a density of $8 \times 10^{4}$ cells $\mathrm{cm}^{-2}$. The cells were first incubated in the presence of their respective culture media in the apical and basal compartments of transwell inserts until they reached confluency. Thereafter, the culture state was changed to ALI. As of the beginning of ALI, dexamethasone was added to the basal medium of A549 cultures. RPMI-1640, DMEM, FBS, PS, GlutaMAX, and Trypsin-EDTA were all Gibco brand.

Silica nanoparticles. Positively charged silica nanoparticles were synthetized by Stöber method and used throughout this study ${ }^{43}$. The nanoparticles contain a core of Cy3 fluorescent molecules $\left(\lambda_{\mathrm{ex}}=550 \mathrm{~nm}\right.$, $\lambda_{\text {em }}=570 \mathrm{~nm}$ ) incorporated during fabrication. The nanoparticles have surface-grafted amine groups affording them a positive surface charge. The diameter of the nanoparticles as obtained from TEM is $41.2 \mathrm{~nm}$ and from DLS is $60 \mathrm{~nm}(\mathrm{pH}<6.0)$.

Pulmonary surfactant. Curosurf (Chiesi Pharmaceuticals) was used as the surfactant model. This porcineoriginated extract is generally used in replacement therapy to cure respiratory distress syndrome in pre-term infants. The stock solution has a concentration of $80 \mathrm{mg} \mathrm{ml}^{-1}$. Curosurf lipids were labeled with the lipophilic fluorescent dye PKH67 $\left(\lambda_{\mathrm{ex}}=490 \mathrm{~nm}, \lambda_{\mathrm{em}}=502 \mathrm{~nm}\right)$ at $10^{-3} \mu \mathrm{mol}$ of PKH67 to $0.8 \mathrm{mg}$ of Curosurf following a previous protocol ${ }^{40}$. Curosurf was provided by Dr. Mostefa Mokhtari (neonatology department of KremlinBicêtre Hospital).

Mixture preparation. To prepare nanoparticle-Curosurf dispersions, we define a mixing ratio parameter $X$ representing the relative concentration of Curosurf to nanoparticles, namely $X=C_{\text {Curo }} / C_{\mathrm{NP}} . X=2$ and 20 were used for cell exposure experiments, while $X=80$ was used for TEM investigations as explained in the following. Nanoparticle-Curosurf mixture at $X=2$ was prepared by first diluting the stock nanoparticle solution to $C_{\mathrm{NP}}=4 \mathrm{mgml}^{-1}$ in Milli-Q water and the stock Curosurf solution to $C_{\text {Curo }}=4 \mathrm{mgml}^{-1}$ in milli-Q water. Then, an appropriate volume of the diluted nanoparticle solution $(50 \mu \mathrm{l}$ for exposure tests on glass and $12.5 \mu \mathrm{l}$ for exposure tests on transwell) was mixed with diluted Curosurf solution at twice that volume. Thereafter, the total volume of the mixture was increased in serum free culture medium in order to obtain a nanoparticle concentration of $C_{\mathrm{NP}}=200 \mu \mathrm{gml}^{-1}$. During exposure to cells, the concentration was further reduced to $C_{\mathrm{NP}}=100 \mu \mathrm{gml}^{-1}$ (see "Exposure treatment" section).

Nanoparticle-Curosurf mixture at a mixing ratio $X=20$ was prepared similarly however the starting concentrations were $21 \mathrm{mg} \mathrm{ml}^{-1}$. Then, an appropriate volume of the diluted nanoparticle solution $(9.5 \mu \mathrm{l}$ for exposure tests on glass and $2.4 \mu \mathrm{l}$ for exposure tests on transwell) was mixed with the diluted Curosurf solution at twenty times that volume. Thereafter, the total volume of the mixture was increased in serum free culture medium in 


\begin{tabular}{|l|l|l|l|l|l|}
\hline Exposure & $m_{N P}(\mu \mathrm{g})$ & $m_{\text {Curo }}(\mu \mathrm{g})$ & $V_{T O T}(\mathrm{ml})$ & $c_{N P}\left(\mu \mathrm{g} \mathrm{ml}^{-1}\right)$ & $m_{N P} / A\left(\mu \mathrm{gc}^{-2}\right)$ \\
\hline Coverslip $\left(\boldsymbol{A}=9.6 \mathbf{c m}^{2}\right)$ & 200 & 0 & 2.0 & 100 & 20.8 \\
\hline Neat nanoparticle & 200 & 400 & 2.0 & 100 & 20.8 \\
\hline $\mathrm{X}=2$ & 199.5 & 4000.5 & 2.0 & 100 & 20.8 \\
\hline $\mathrm{X}=20$ & 0 & 400 & 2.0 & 0 & 0 \\
\hline Neat Curosurf & 0 & \multicolumn{5}{|l|}{} \\
\hline Transwell $\left(\boldsymbol{A}=1.12 \mathbf{c m}^{2}\right)$ & 50 & 0.5 & 100 & 44.6 \\
\hline Neat nanoparticle & 50 & 0 & 0.5 & 100 & 44.6 \\
\hline $\mathrm{X}=2$ & 50 & 100 & 0.5 & 100 & 44.6 \\
\hline $\mathrm{X}=20$ & 50.4 & 1000 & 0.5 & 0 & 44.6 \\
\hline Neat Curosurf & 0 & 100 & 0.5 & \\
\hline
\end{tabular}

Table 1. Exposure concentrations on coverslip and transwell.

order to obtain a nanoparticle concentration of $200 \mu \mathrm{g} \mathrm{ml}^{-1}$. During exposure to cells, the concentration was further reduced to $100 \mu \mathrm{g} \mathrm{ml}^{-1}$ (see "Exposure treatment" section).

All sample preparations were performed immediately prior to cell exposure. The serum-free culture media were respectively RPMI-1640 and DMEM for NCI-H441 and A549. The total mixture volumes were respectively $2 \mathrm{ml}$ and $500 \mu \mathrm{l}$ in exposure tests on coverslip and on transwell. A summary of the exposure conditions is provided in Table 1, and the extended calculations in S3 and S4.

Finally, nanoparticle-Curosurf mixture at $X=80$ was prepared for TEM investigations. Here, $100 \mu$ of Curosurf stock solution $\left(80 \mathrm{mg} \mathrm{ml}^{-1}\right.$ ) was mixed with $100 \mu \mathrm{l}$ of nanoparticle solution at a concentration of $1 \mathrm{mg} \mathrm{ml}^{-1}$.

Exposure treatment. Cultures were first rinsed with PBS to remove dead cells. Then, serum free medium was added to the cells to a volume of $1 \mathrm{ml}$ for exposure tests on coverslip and $250 \mu \mathrm{l}$ on transwell. Thereafter, an equal volume of mixture (see Mixture preparation) was added. The cells were incubated during $24 \mathrm{~h}$ in an atmosphere of $5 \% \mathrm{CO}_{2}$ at $37^{\circ} \mathrm{C}$. Thereafter, the supernatant was discarded, and the cells were rinsed with PBS to remove remaining nanoparticles and Curosurf vesicles, as well as the dead cells. Each exposure condition, namely neat nanoparticles, $X=2$ and $X=20$, was tested in duplicate.

Cell fixation and immunostaining of nuclei. The cells were fixed with $4 \%$ paraformaldehyde (PFA) in PBS, and then the nuclei were stained with DAPI. The cell-side of the coverslip was then wetted with PBS, and mounted and sealed to a glass slide using Gene Frame adhesive (ABgene Advanced Biotech). The transwell membranes were first cut using a scalpel, then the cell-side was wetted with Fluoroshield (Sigma-Aldrich), and mounted and sealed to a glass slide using a Gene Frame and a coverslip support.

Barrier integrity immunolabelling and microscopy. A549 and NCI-H441 were grown on transwell for 2 weeks, washed with PBS and fixed with 4\% PFA in PBS for $10 \mathrm{~min}$ at ambient temperature. Inserts were washed, permeabilized with $0.1 \%$ Triton X-100 in PBS for 2 min, and then blocked with $2 \%$ FBS in PBS for $60 \mathrm{~min}$ at ambient temperature. Membranes were carefully excised and transferred to a humidified container for primary antibody binding. This was carried out overnight at $4{ }^{\circ} \mathrm{C}$, using a mixture of mouse anti-human $\mathrm{ZO}-1$ and goat anti-human claudin 4 antibodies, both at 1:200 dilution in blocking buffer. Membranes were gently washed to remove unbound primary antibody, and were then incubated with a mixture of donkey anti-goat 594 and donkey anti-mouse 647 secondary antibodies for $60 \mathrm{~min}$ at ambient temperature. Samples were finally washed and mounted using soft mountant containing DAPI. Imaging was carried out on a Zeiss LSM 710, with the pinhole set to give $1 \mu \mathrm{m}$ slices at each wavelength. Images shown are maximum projections of these stacks.

Transepithelial electrical resistance. The barrier integrity of the epithelia formed by NCI-H441 and A549 on transwell inserts was monitored by collecting the transepithelial electrical resistance (TEER). TEER was measured using EVOM2 Epithelial Volt/ohm meter along with Endohm12 chamber (World Precision Instrument) every 2-3 days as of day-0 of ALI. After sterilization with ethanol $70 \%$, the chamber was rinsed and then filled with $2 \mathrm{~mL}$ of $\mathrm{HBSS}$ containing $\mathrm{Ca}^{2+}, \mathrm{Mg}^{2+}$ ions and glucose. The top compartment of transwell inserts was filled with $500 \mu \mathrm{L}$ of HBSS and successively transferred in the chamber. The resistance value in $\Omega$ units was read after the stabilization of TEER signal. The value was subtracted by a background resistance due to transwell insert. The resulting value was subsequently multiplied by the surface area of transwell insert equal to $1.12 \mathrm{~cm}^{2}$.

Transmission electron microscopy. A dispersion was prepared by simple mixing equal volumes of $80 \mathrm{mg} \mathrm{ml}^{-1}$ Curosurf and $1 \mathrm{mg} \mathrm{ml}^{-1}$ silica nanoparticles. The dispersion was fixed with $2.5 \%$ glutaraldehyde and $4 \%$ PFA in PBS buffer. The sample was stored in the fixative for $3 \mathrm{~h}$ at room temperature and then kept at $4{ }^{\circ} \mathrm{C}$ before next preparations. Afterwards, the sample was centrifuged at 500-1000 g for 3 min to obtain a pellet. After several washing steps in buffer, the sample was subsequently post-fixed in osmium tetroxide, dehydrated in an ascending ethanol series and embedded in Epon at $60^{\circ} \mathrm{C}$. The Eppendorf cups were then removed, and ultrathin 70-nm sections were cut using an ultramicrotome UC6 (Leica). The sections were analyzed with a 120- 


\begin{tabular}{|l|l|}
\hline Nanoparticle & Silica, $\mathrm{SiO}_{2}$ \\
\hline${ }^{\mathrm{a}}$ Diameter, $D$ & $41.2 \mathrm{~nm}$ \\
\hline${ }^{\mathrm{b}}$ Diameter, $D_{\mathrm{h}}(\mathrm{DI}$-water, $\mathrm{pH}<6.0)$ & $60.0 \mathrm{~nm}$ \\
\hline${ }^{\mathrm{b}}$ Diameter, $D_{\mathrm{h}}$ in serum-free DMEM & $1300 \mathrm{~nm}$ \\
\hline b Diameter, $D_{\mathrm{h}}$ in serum-free RPMI & $1200 \mathrm{~nm}$ \\
\hline Surface functional group & Amine \\
\hline Surface charge density & $+0.62 e \mathrm{~nm}^{-2}$ \\
\hline Zeta potential $($ DI-water, $\mathrm{pH}<6.0)$ & $50 \mathrm{mV}$ \\
\hline
\end{tabular}

Table 2. Summary of the physicochemical characteristics of nanoparticles. ${ }^{\mathrm{a}} \mathrm{TEM}$; ${ }^{\mathrm{b}} \mathrm{DLS}$.

$\mathrm{kV}$ transmission electron microscope Tecnai 12 (ThermoFisher Scientific) using the 4-k camera OneView and the GMS3 software (Gatan).

Fluorescence microscopy. Fluorescence microscopy images were obtained using an IX73 inverted microscope (Olympus) with a $10 \times$ objective (N.A. 0.3), an ExiBlue camera (QImaging), an XCite illumination system and MetaVue imaging software. The sample was illuminated, and the red fluorescence signal obtained via an excitation filter and an emission filter. The $2 \mathrm{D}$ signal intensity was averaged along the y-direction in the field of view, resulting in a $1 \mathrm{D}$ signal along the $\mathrm{x}$-direction, using the Plot Profile plugin of ImageJ. For high intensity signals, e.g. in the case of exposure to neat nanoparticles, a background correction was applied: from the 1D signal, an intensity corresponding to cells alone fluorescence was subtracted. For weak signals, e.g. in the exposure conditions of $\mathrm{X}=2$ and $\mathrm{X}=20$, the background correction was accomplished on KaleidaGraph software (Synergy) using a weighted curve fit function. In this case, from the original signal, the weighted fit function was subtracted.

Confocal microscopy. Confocal microscopy images were acquired using a spinning disk confocal inverted microscope (Olympus IX81) with a $60 \times$ oil-immersion objective (N.A. 1.42) provided with an EMCCD camera (Andor iXon 897), a NanoScanZ z-axis nano-positioning stage (Prior Scientific), and iQ3 software (Andor). Nanoparticles were excited with a 561-nm wavelength laser line, PKH67-labeled Curosurf was excited at $488 \mathrm{~nm}$, and DAPI at $405 \mathrm{~nm}$. Exposure time, gain and laser intensity were identical in all acquisitions. Image stacks were collected with $\mathrm{z}$-step of $0.25 \mu \mathrm{m}$. Image processing was performed with ImageJ.

\section{Results}

Silica nanoparticle-curosurf dispersions. The silica nanoparticles were thoroughly characterized ${ }^{39}$, and a summary of their physicochemical properties is provided in Table 2. The nanoparticles have a hydrodynamic diameter equal to $60 \mathrm{~nm}$ at $\mathrm{pH}<6.0$, which increases to $1280 \mathrm{~nm}$ in PBS, and to $1200-1300 \mathrm{~nm}$ in serum free culture media. Of note, aggregation in physiological media occurs rapidly $(<1 \mathrm{~s})$ upon dilution in media. The reason is that the electrostatic interactions between nanoparticles are screened following variation in $\mathrm{pH}$ and ionic strength. TEM images of the nanoparticles showing a diameter equal to $41.2 \mathrm{~nm}$ are provided in S5. DLS analysis of nanoparticle size in DMEM and RPMI is provided in S6.

Considering that native surfactant is not readily available, Curosurf, which is a clinical surfactant substitute used for treatment of RDS, is a valuable choice for in vitro investigations. The chemical composition of Curosurf and that of native pulmonary surfactant is provided in S2. The two surfactant fluids are somewhat similar with respect to lipid composition, but differ in their protein compositions. One example is the absence of protein SP-A in Curosurf which is associated with tubular myelin formation in native surfactant ${ }^{18}$. Cholesterol which is responsible for less-ordered lipid structures in native surfactant is also absent in Curosurf ${ }^{18}$. Despite these differences, using cryo-TEM, we show that the lipid structures such as uni- or, multi- lamellar/vesicular structures with sizes ranging from a few tens of nanometers to about $2 \mu \mathrm{m}$ are present in Curosurf $\mathrm{f}^{26,39}$. These images are presented in S7.

The silica nanoparticle-Curosurf dispersion at $X=80$ was investigated using TEM. This mixing ratio is smaller than the estimated mixing ratio in occupational exposure which is of the order of $10^{429}$. Despite such difference, a lower mixing ratio was used to provide sufficient nanoparticle density for TEM observations.

Several examples of $70-\mathrm{nm}$ sections of microscopic samples are shown in Fig. 2. When mixed with nanoparticles, Curosurf is observed to retain its vesicular structure, e.g. the images in Fig. 2 show the presence of uni- and multi-lamellar/vesicular structures, similar to cryo-TEM images of pristine Curosurf (S7). Within the multivesicular structure shown in Fig. 2a, individual vesicles, multi-vesicular vesicles as well as lamellar structures are observed. These structures are distributed in the area confined by the outer membrane, which appears to be disintegrated in the upper part of the image marked with an arrow. The observed fluctuations in the contour of all membranes is associated with surface tension or elastic properties of the membrane. Generally, these fluctuations are expected to occur when the liquid volume inside a membrane is reduced resulting in a reduction in membrane pressure and contour fluctuation ${ }^{44}$.

Figure $2 \mathrm{~b}$ shows a multilamellar vesicle with a size of about $2.2 \mu \mathrm{m}$. The overall structure is again well preserved after treatment, and one observes densely packed lamella with gap distances between $20-100 \mathrm{~nm}$. This densely packed onion-like structure is reminiscent of multilamellar vesicles found in lipids as well as in 

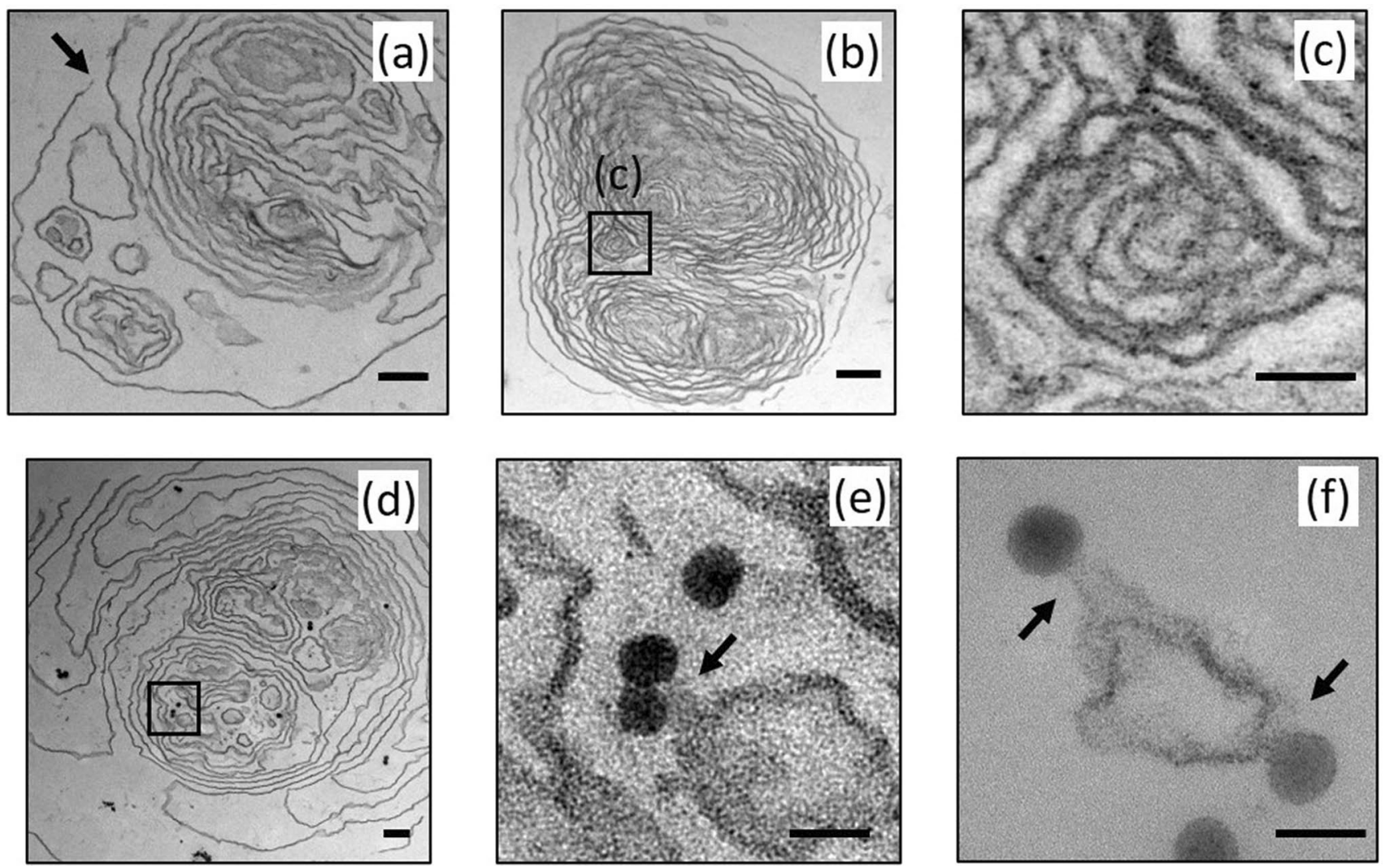

Figure 2. Transmission electron microscopy (TEM) images of positively charged silica nanoparticleCurosurf dispersion at a mixing ratio equal to $\mathrm{X}=80$. (a) A multivesicular structure containing single vesicles, multivesicular vesicles, and lamellar structures. Arrow points at a disintegration site. (b) A multilamellar vesicle with a size of about $2.2 \mu \mathrm{m}$ and interlamellar spacing 20-100 nm. Boxed area is enlarged in (c). (c) An inner structure inside a multilamellar vesicle showing lipid membranes with thickness of $5 \mathrm{~nm}$ and interlamellar spacing of a few tens of nm. (d) A multivesicular structure enclosing several nanoparticles in singlets, doublets and triplets. Boxed area shows a single particle and a doublet in the vicinity of lipid membranes. The boxed area is enlarged in (e). A total of 18 nanoparticles is found in this 70-nm section. (e) The enlarged boxed area in $\mathrm{d}$. The doublet is in contact with the neighboring lipid membrane as marked with an arrow. (f) Nanoparticles forming adhesion contacts with lipid membranes are marked with arrows. Scale bar $200 \mathrm{~nm}(\mathbf{a}, \mathbf{b}, \mathbf{d}), 50 \mathrm{~nm}$ $(\mathbf{c}, \mathbf{e}, \mathbf{f})$.

surfactant phases ${ }^{18}$. An enlarged section of an inner membranous structure is shown in Fig. $2 \mathrm{c}$ in which membrane thickness equal to $5 \mathrm{~nm}$ and interlamellar spacing in a range of a few tens of $\mathrm{nm}$ are clear. It is noted that the multivesicular/lamellar structures of Fig. 2a,b are devoid of nanoparticles. This is due to a low concentration of nanoparticles at a mixing ratio of $\mathrm{X}=80$.

The multivesicular structure shown in Fig. $2 \mathrm{~d}$ contains several nanoparticles dispersed throughout its volume with some nanoparticles visible inside the inner membranes giving in total 14 nanoparticles in this 70 -nm section. A close inspection of internal nanoparticles reveals that no SLB is formed around them. An enlarged view of selected nanoparticles is shown in Fig. 2e. In this example, it is observed that the nanoparticles come into contact and adhere to the lipid membranes as marked with an arrow on this image. This is resulting from electrostatic interactions between positively charged silica and vesicle membranes: a surface charge density of $+0.62 e \mathrm{~nm}^{-2}$ drives the electrostatic interactions between the nanoparticles and the negative surface potential of surfactant vesicles, about $-54 \mathrm{mV}^{26}$. However in larger interlamellar gaps, nanoparticles are found in proximity but not adherent to the lipids. In Fig. 2f, more examples of nanoparticle-lipid adhesion contacts are marked with arrows.

In general, we find at a mixing ratio of $\mathrm{X}=80$ that nanoparticles interact with surfactant lipids resulting in penetration inside the vesicles or adhesion to membranes. However, nanoparticles are also found in proximity to the membranes but not adhering to them. In accordance with DLS data, by increasing nanoparticle concentration for example at a mixing ratio of $\mathrm{X}=2$, the number of interactions is enhanced resulting in large nanoparticlesurfactant lipid aggregates. It is expected that these interactions can affect the contact of nanoparticles with the alveolar cells. These effects are investigated in below.

Integrity of cell barrier. A characteristic feature of epithelial cells is the formation of tight junctions between adjacent cells which prevent diffusion of material across the epithelium. Paracellular permeability is controlled via expression, localization and interaction of proteins that form tight junctions such as claudins, 


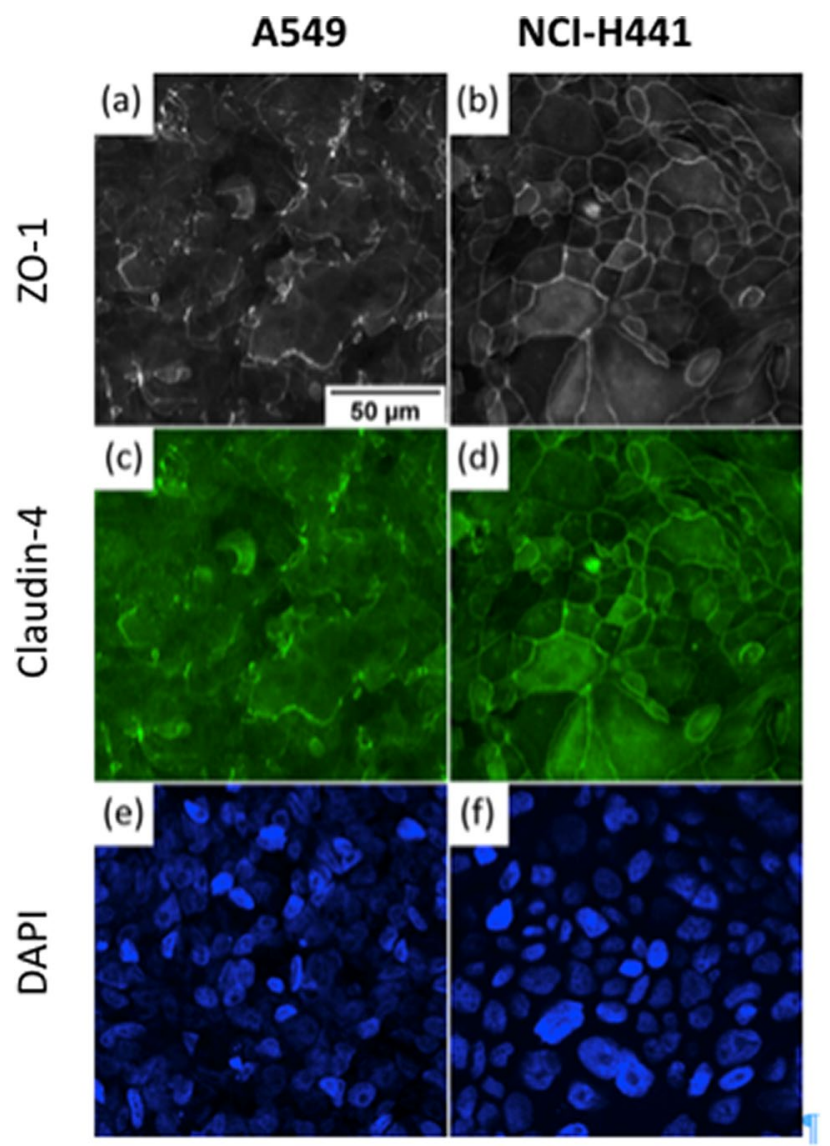

Figure 3. Distribution of tight junction proteins in A549 and NCI-H441. A549 and NCI-H441 (images on the left and right, respectively) were cultured in ALI condition for two weeks. They were then fixed and immunostained to reveal ZO-1 (a,b) and claudin-4 (c,d). Despite maintaining a compact monolayer (DAPI nuclear staining, e,f), A549 exhibits uneven formation of tight junctions where ZO1 and claudin-4 tightly colocalize along the periphery between adjacent cells. NCI-H441 demonstrates much more consistent tight junction formation. Scale bar $50 \mu \mathrm{m}$.

occludin and ZO- $1^{45}$. Using immunostaining, we visualized ZO-1, which anchors the tight junction to actin cytoskeleton, and claudin-4, one of the main sealing proteins that closes the paracellular junction in distal lung epithelium. Examples of the immunostaining images are shown in Fig. 3. From this figure, it was evident that the localization of these key proteins is closely related, but that specific junctional localization is much less consistent in A549 than in NCI-H441. In particular, the distribution of ZO-1 and claudin-4 in A549, respectively in Fig. 3a,c, is patchy and dispersed. However, the distribution of these proteins in NCI-H441, respectively shown in Fig. 3b,d, is present all around the cells. In both cases however a compact monolayer of cells was maintained as evidenced from DAPI nuclear staining (Fig. 3e,f).

The integrity of the barrier was monitored using TEER. A high resistance is associated with a barrier that is less permeable to small ions in the solution. We started to monitor the resistance three days post cell seeding, when ALI was first established. The TEER values for A549 are shown in Fig. 4. With A549, the transepithelial resistance did not exceed $40 \Omega \mathrm{cm}^{2}$ over the course of the cell culture. A low resistance indicates a deficit in the formation of functional tight junctions, consistent with the observed non-uniform distribution of the key proteins (Fig. 3). The TEER values of NCI-H441 are also shown in Fig. 4. With this cell line, an initial reduction in the resistance was obtained which is probably associated with changes in the organization of the cells after the initiation of ALI. Around 7 days post cell seeding ( 4 days post ALI) the resistance starts to increase gradually. The resistance then reaches a plateau at a value of about $200-300 \Omega \mathrm{cm}^{2}$ around 15 days post cell seeding (12 days post ALI) consistent with formation of a tight barrier.

Nanoparticle-cell interaction. We investigated the protective role of pulmonary surfactant in vitro by exposing A549 and NCI-H441 to dispersions of positively charged silica nanoparticles and Curosurf. For experiments on coverslips, the cells were exposed to dispersions 2 days after seeding. For experiments on transwell, the cells were exposed generally 15 days post cell seeding (12 days post ALI) when NCI-H441 cells had formed functional epithelial barriers, as evidenced by a TEER $\geq 200 \Omega \mathrm{cm}^{2}$. The same time schedule was used for A549 cells cultured on transwell, although the TEER of A549 cells did not exceed $40 \Omega \mathrm{cm}^{2}$. The cells were exposed to dispersions for $24 \mathrm{~h}$. 


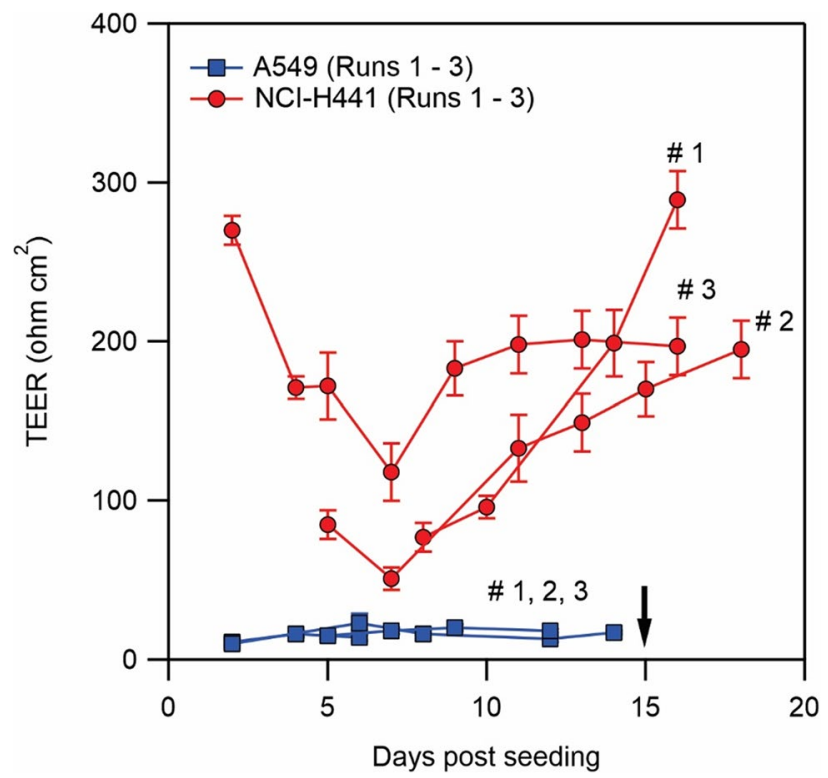

Figure 4. Transepithelial electrical resistance (TEER) measured for A549 and NCI-H441. ALI was stablished on day 3 post cell seeding when TEER measurements commenced. Nanoparticle exposure was performed after day 15 marked with a black arrow when TEER of NCI-H441 was above $200 \Omega \mathrm{cm}^{2}$. Independent experiments were performed on different occasions and in each occasion on at least 3 transwell. Error bar is standard deviation for several transwell in a same experiment.

The dispersions included neat silica nanoparticles at $C_{N P}=100 \mu \mathrm{g} \mathrm{ml}^{-1}$, silica-Curosurf dispersions at $\mathrm{X}=2$ $\left(C_{N P}=100 \mu \mathrm{g} \mathrm{ml}^{-1}, C_{C u r o}=200 \mu \mathrm{g} \mathrm{ml}^{-1}\right)$ and $\mathrm{X}=20\left(C_{N P}=100 \mu \mathrm{g} \mathrm{ml}^{-1}, C_{\text {Curo }}=2000 \mu \mathrm{g} \mathrm{ml}^{-1}\right)$, and neat Curosurf at $C_{\text {Curo }}=200 \mu \mathrm{g} \mathrm{ml}^{-1}$. We note that $\mathrm{X}=2$ exposure condition corresponds to the peak of light scattering intensity of dispersions signifying a mixing ratio where the interactions result in largest aggregates ${ }^{26}$. The condition $\mathrm{X}=20$ is closer to the estimated mixing ratio in the lungs ${ }^{29}$. The results of these DLS measurements are presented in S8.

Furthermore, the choice of the aforementioned concentrations is driven from the cellular viability assays which are summarized in S9. We find in the absence of serum that the onset of cytotoxic effects leading to loss of cellular viability is $C_{N P}=100 \mu \mathrm{g} \mathrm{ml}^{-1}$. No significant loss of viability is observed at lower concentrations with these nanoparticles. In the presence of serum however over a wide range of nanoparticle concentrations up to $C_{N P}=1000 \mu \mathrm{g} \mathrm{ml}^{-1}$ no loss of viability is observed. If Curosurf is added to nanoparticle solution at $\mathrm{X}=20$, no loss of viability is again observed even without the presence of the serum. From these results, we fixed the nanoparticle concentration at $100 \mu \mathrm{g} \mathrm{ml}^{-1}$, and varied between without and with surfactant conditions, while the latter condition was investigated at two relative concentrations of surfactant, namely $\mathrm{X}=2$ and 20.

Under the present exposure conditions, the mass of nanoparticles was $200 \mu \mathrm{g}$ for exposure on coverslip and $50 \mu \mathrm{g}$ for exposure on transwell. Correspondingly, the surface concentration of nanoparticles was $20.8 \mu \mathrm{g} \mathrm{cm}^{-2}$ on coverslip and $44.6 \mu \mathrm{g} \mathrm{cm}^{-2}$ on transwell. A summary of the exposure conditions is provided in Table 1. A complete overview of the preparation and exposure concentrations is provided in S3 \& S4.

The investigations were performed using fluorescence microscopy to quantify nanoparticle uptake in each exposure condition. Confocal microcopy was used to localize the silica nanoparticles and Curosurf lipids at single cell level in addition to semi-quantification of the area fraction of nanoparticles per individual cells.

Quantification of nanoparticle uptake. After exposure for $24 \mathrm{~h}$, the cells were fixed and observed under fluorescence microscopy for quantification of nanoparticle uptake. Figure 5 shows images of A549 cultured on coverslip $(\mathrm{a}, \mathrm{b})$ and on transwell $(\mathrm{c}, \mathrm{d})$. In these images, the red fluorescence signal and the phase contrast image are superimposed. On coverslip, the cell layer is more than $90 \%$ confluent in selected regions while on transwell the confluency is $100 \%$. The images represent two exposure conditions, namely neat nanoparticle (a, c) and nanoparticle-Curosurf dispersion at $\mathrm{X}=2(\mathrm{~b}, \mathrm{~d})$. The images were acquired using a $10 \times$ objective with a wide field of view of $\sim 0.9 \times 0.7 \mathrm{~mm}^{2}$ thus giving access to a large surface area for the quantification. Comparing Fig. 5a (resp. Figure 5c) to Fig. 5b (resp. Figure 5d), it is evident that the amount of nanoparticles is reduced when Curosurf is present. While in the neat exposure condition, a uniform distribution of nanoparticle patches is observed on both coverslip and on transwell, these patches are less frequent in the presence of Curosurf. To quantify this reduction, we integrated the intensity of the red fluorescence signal for each exposure condition and the resulting values are shown in Fig. 5e,f. Thereby, the integrated intensity of samples exposed to the same surface concentration of nanoparticles in the absence of surfactant is found to be much higher than when Curosurf is present. In particular, a reduction in the integrated intensity of up to two orders of magnitude on glass, e.g. $\sim 4000$ counts per second (cps) vs. $\sim 40 \mathrm{cps}$, and an order of magnitude on transwell, e.g. $\sim 13000 \mathrm{cps}$ vs. 

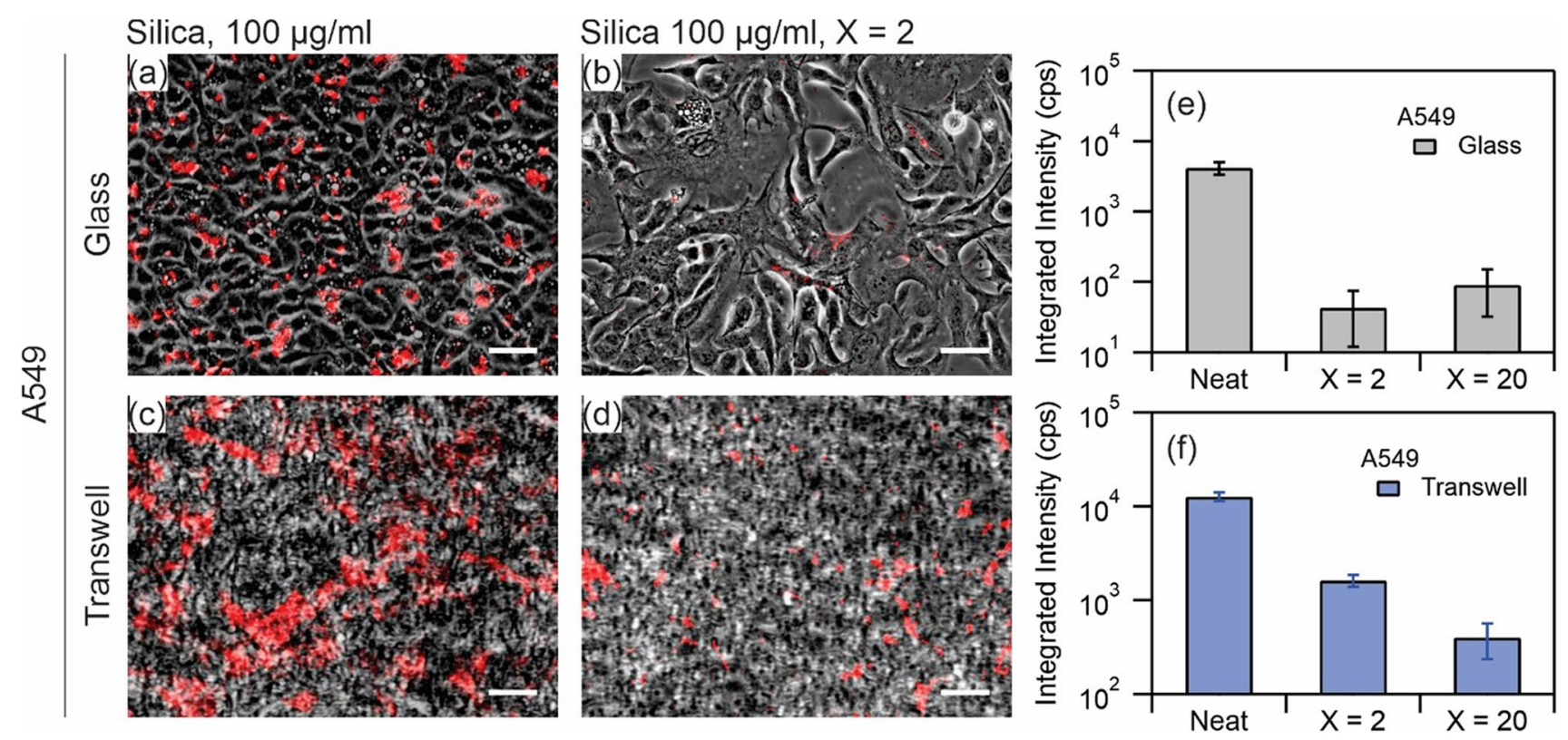

Figure 5. (a-d) Superimposed red fluorescence and phase contrast images of A549 exposed to silica nanoparticles at $100 \mu \mathrm{g} \mathrm{ml}^{-1}(\mathbf{a}, \mathbf{c})$ and silica nanoparticles at $100 \mu \mathrm{g} \mathrm{ml}^{-1}$ mixed with Curosurf at $200 \mu \mathrm{g} \mathrm{ml} l^{-1}$, $\mathrm{X}=2(\mathbf{b}, \mathbf{d})$, on glass $(\mathbf{a}, \mathbf{b})$ and on transwell $(\mathbf{c}, \mathbf{d})$. Scale bar $50 \mu \mathrm{m}(\mathbf{a}, \mathbf{b})$ and $25 \mu \mathrm{m}(\mathbf{c}, \mathbf{d}) .(\mathbf{e}, \mathbf{f})$ Quantitative analysis of integrated intensity of the fluorescence signal from the three exposure conditions, namely silica at $100 \mu \mathrm{g} \mathrm{ml}^{-1}$ and silica at $100 \mu \mathrm{g} \mathrm{ml}^{-1}$ mixed with Curosurf at $200 \mu \mathrm{g} \mathrm{ml}^{-1}(\mathrm{X}=2)$ and $2 \mathrm{mg} \mathrm{ml}^{-1}(\mathrm{X}=20)$. Each exposure condition was tested in duplicates.

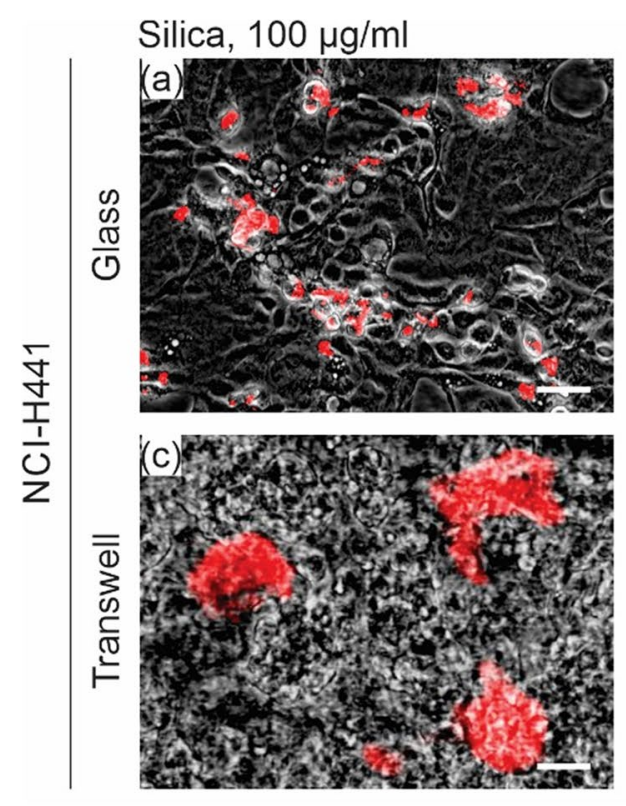

Silica $100 \mu \mathrm{g} / \mathrm{ml}, \mathrm{X}=2$
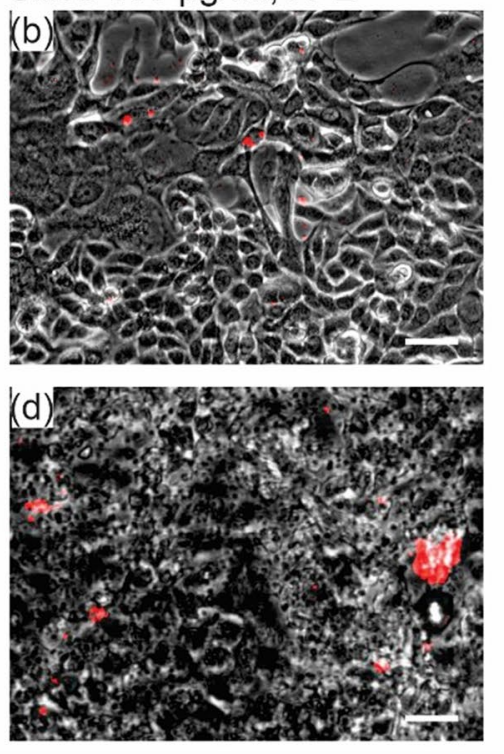
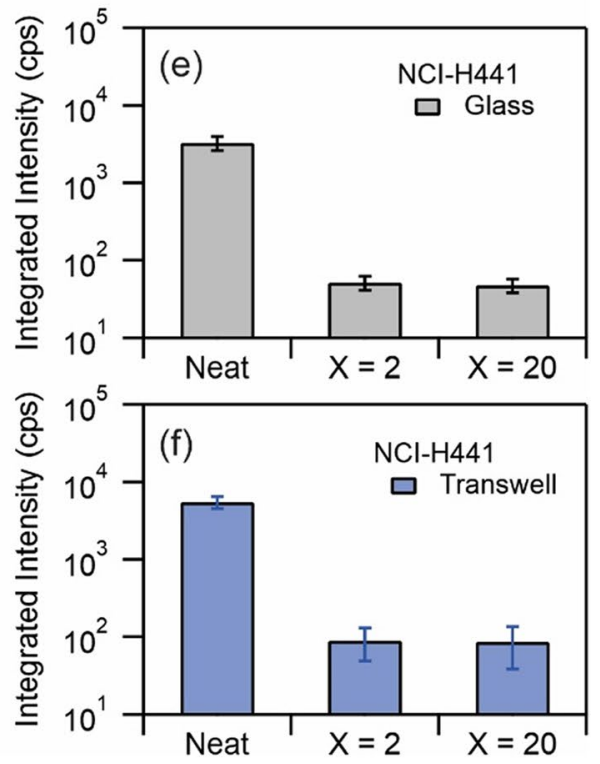

Figure 6. (a-d) Superimposed red fluorescence and phase contrast images of NCI-H441 exposed to silica nanoparticles at $100 \mu \mathrm{g} \mathrm{ml}^{-1}$ (a,c) and silica nanoparticles at $100 \mu \mathrm{g} \mathrm{ml}^{-1}$ mixed with Curosurf at $200 \mu \mathrm{g} \mathrm{ml} \mathrm{g}^{-1}$, $X=2(\mathbf{b}, \mathbf{d})$, on glass $(\mathbf{a}, \mathbf{b})$ and on transwell $(\mathbf{c}, \mathbf{d})$. Scale bar $50 \mu \mathrm{m}(\mathbf{a}, \mathbf{b})$ and $25 \mu \mathrm{m}(\mathbf{c}, \mathbf{d})$. (e,f) Quantitative analysis of integrated intensity of the fluorescence signal from the three exposure conditions, namely silica at $100 \mu \mathrm{g} \mathrm{ml}^{-1}$ and silica at $100 \mu \mathrm{g} \mathrm{ml}^{-1}$ mixed with Curosurf at $200 \mu \mathrm{g} \mathrm{ml}^{-1}(\mathrm{X}=2)$ and $2 \mathrm{mg} \mathrm{ml}^{-1}(\mathrm{X}=20)$. Each exposure condition was tested in duplicates.

$\sim 2000 \mathrm{cps}$, are observed when Curosurf is present. Additional increase in the amount of Curosurf to the exposure condition $\mathrm{X}=20$ further reduces the amount of nanoparticles retained by A549 cells on transwell, and we conclude that pulmonary surfactant inhibits the uptake of positively charged silica nanoparticles by A549 cells.

Figure 6 shows similar images for NCI-H441 cultured on coverslip $(a, b)$ and on transwell $(c, d)$. The images represent the exposure conditions, namely neat nanoparticles ( $a, c)$ and silica-Curosurf dispersion at $\mathrm{X}=2$ (b, d). As before, the distribution of nanoparticles is visibly different between the two exposure conditions (Fig. 6a vs. 


\begin{tabular}{|c|c|c|c|c|c|c|c|c|}
\hline \multirow{2}{*}{$\begin{array}{l}\text { Substrate } \\
\text { Exposure condition to silica nanoparticles }\end{array}$} & \multicolumn{4}{|c|}{ Glass coverslip } & \multicolumn{4}{|c|}{ Transwell } \\
\hline & Neat & $X=2$ & $\mathrm{X}=\mathbf{2 0}$ & $\begin{array}{l}\text { Ratio } \\
X=20 / \text { Neat }\end{array}$ & Neat & $X=2$ & $\mathrm{X}=\mathbf{2 0}$ & $\begin{array}{l}\text { Ratio } \\
X=20 / \text { Neat }\end{array}$ \\
\hline \multicolumn{9}{|l|}{ NCI-H441 } \\
\hline Integrated intensity ${ }^{\mathrm{a}}$ & 3290 & 52 & 48 & 0.015 & 5515 & 90 & 86 & 0.016 \\
\hline Area fraction ${ }^{\mathrm{b}}$ & 9.8 & 0.5 & 0.2 & 0.020 & 9.7 & 0.2 & 1 & 0.021 \\
\hline \multicolumn{9}{|l|}{ A549 } \\
\hline Integrated intensity ${ }^{\mathrm{a}}$ & 4161 & 43 & 91 & 0.022 & 12,701 & 1614 & 402 & 0.032 \\
\hline Area fraction ${ }^{\mathrm{b}}$ & 15.5 & 0.9 & 0.2 & 0.013 & 15.2 & 4.7 & 1.6 & 0.105 \\
\hline
\end{tabular}

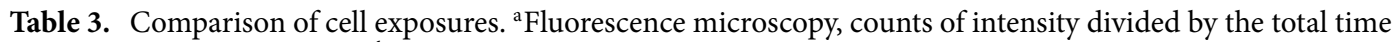
of exposure in seconds (cps). ${ }^{b}$ Confocal microscopy, \%.

Fig. 6 b and Fig. $6 \mathrm{c}$ vs. Fig. 6d), and while clusters of nanoparticle aggregates are observable across the cell layer in exposure to neat nanoparticles, these are less frequent when Curosurf is present. The observed reduction is consistent with cells cultured on glass and on transwell. The values of the integrated intensity are shown in Fig. 6e for NCI-H441 on glass and Fig. $6 \mathrm{f}$ on transwell. A reduction by about two orders of magnitude is observed in the integrated intensity (e.g. $\sim 3000 \mathrm{cps}$ vs. $\sim 50 \mathrm{cps}$ on glass, $\sim 6000 \mathrm{cps}$ vs. $\sim 90 \mathrm{cps}$ on transwell) between the exposure to neat silica nanoparticles and to silica-Curosurf dispersion. Such a reduction indicates that the presence of Curosurf reduces the amount of nanoparticles taken up by NCI-H441, as it did for A549.

The capacity of the two cell lines to adsorb or internalize nanoparticles differs, and whereas A549 exhibited a uniform distribution of nanoparticle fluorescence across the population after $24 \mathrm{~h}$ exposure without Curosurf, NCI-H441 showed a heterogeneous pattern of retention, with isolated cells or patches of cells adsorbing large quantities of nanoparticles while others exhibited little to no retention. This likely arises from underlying differences between the two cell lines in terms of cell uptake processes. Prior research suggests that A549 takes up nanoparticles of this approximate size via clathrin- or caveolin-mediated endocytosis, and does not express flotillin proteins ${ }^{46}$, whereas NCI-H441 exhibits at least some degree of flotillin-dependent nanoparticle uptake ${ }^{47}$. Despite these differences between cell lines, the integrated intensity of nanoparticle fluorescence is reduced by one to two orders of magnitude when nanoparticles are exposed to cells together with Curosurf at X=2, as compared to nanoparticle exposure without surfactant. This reduction again supports a protective role for surfactant against silica nanoparticles. The results of fluorescence microscopy measurements are summarized in Table 3.

Localization of nanoparticles and lipids. Figure 7 shows confocal microscopy images of A549 cultured on coverslip (Fig. 7a,b) and on transwell (Fig. 7c,d). The representative images are from two exposure conditions, namely neat silica nanoparticles (Fig. 7a,c) and silica nanoparticle-Curosurf dispersion at $\mathrm{X}=2$ (Fig. 7b,d). Figure 7a shows a maximum projection of a confocal stack, superimposed over a corresponding phase contrast view of the same region, and a corresponding orthogonal projection to the right of this. The A549 in this image was cultured on a coverslip and exposed to nanoparticles in suspension at a concentration of $100 \mu \mathrm{g} \mathrm{ml}^{-1}$ without surfactant. The phase contrast image shows formation of several vacuoles $(1-10 \mu \mathrm{m})$ in the cells in this exposure condition. We have previously observed a similar response with these cells upon exposure to similar nanoparticles ${ }^{39}$. The vacuoles appear to not contain nanoparticles. This observation suggests that although their formation is part of cellular response to nanoparticle exposure, they do not directly participate in the internalization process. The orthogonal image depicts a section along the direction of triangle showing nanoparticle aggregates at the level or below the nuclei. Figure $7 \mathrm{~b}$ shows an example of identical cells exposed to silica-Curosurf dispersion at $\mathrm{X}=2$. In this case, the intracellular vacuoles are not visible anymore. This observation which shows the effect of pulmonary surfactant on eliminating one possible cytotoxic cellular response is again consistent with the behavior of these cells in exposure to SLB-coated silica nanoparticles ${ }^{39}$. Moreover, we find that the amount of internalized or surface bound nanoparticles is reduced in exposure to $\mathrm{X}=2$ condition. We also find that the nanoparticles colocalize with surfactant lipids: yellow spots resulting from superimposed red fluorescence signal from silica nanoparticles and green fluorescence signal from Curosurf lipids. The orthogonal view shows that the colocalized nanoparticle-lipid aggregates are at the level of the nuclei in this view. Observation of green aggregates (in $\mathrm{x}-\mathrm{y}$ and $\mathrm{y}-\mathrm{z}$ views) reveals that surfactant lipids may also be internalized by the cells or bound to the cell surface.

The exposure conditions in Fig. 7c,d are similar to Fig. 7a,b; however, the cells were cultured on transwell in these cases. Again, one observes aggregates when nanoparticles were incubated with the cells (Fig. 7c) and that the number of these aggregates is reduced in the presence of surfactant (Fig. 7d). Similar to Fig. 7b, the observed aggregates in Fig. 7d are found to colocalize with surfactant lipids and are visible as yellow spots. However, unlike exposure on glass, the orthogonal views in Fig. $7 \mathrm{c}$,d show that the aggregates were accumulated in the upper part and above the nuclei in exposure on transwell.

From these images it is possible to estimate the area fraction of nanoparticles uptaken per individual cells in each exposure condition. Figure 7e (resp. 7f.) shows that the area is much higher in the exposure to neat nanoparticles than when Curosurf was present at $X=2$, consistent on both coverslip and on transwell. Moreover, additional increase in surfactant concentration further decreases the area. These observations are in agreement with the results of fluorescence microcopy for A549 shown in Fig. 5.

Figure 8 (a-d) show similar confocal images for NCI-H441. These cells were again cultured on coverslip (Fig. 8a,b) or on transwell (Fig. 8c,d), and were incubated with neat silica nanoparticles at $100 \mu \mathrm{g} \mathrm{ml}^{-1}$ (Fig. 8a,c) 

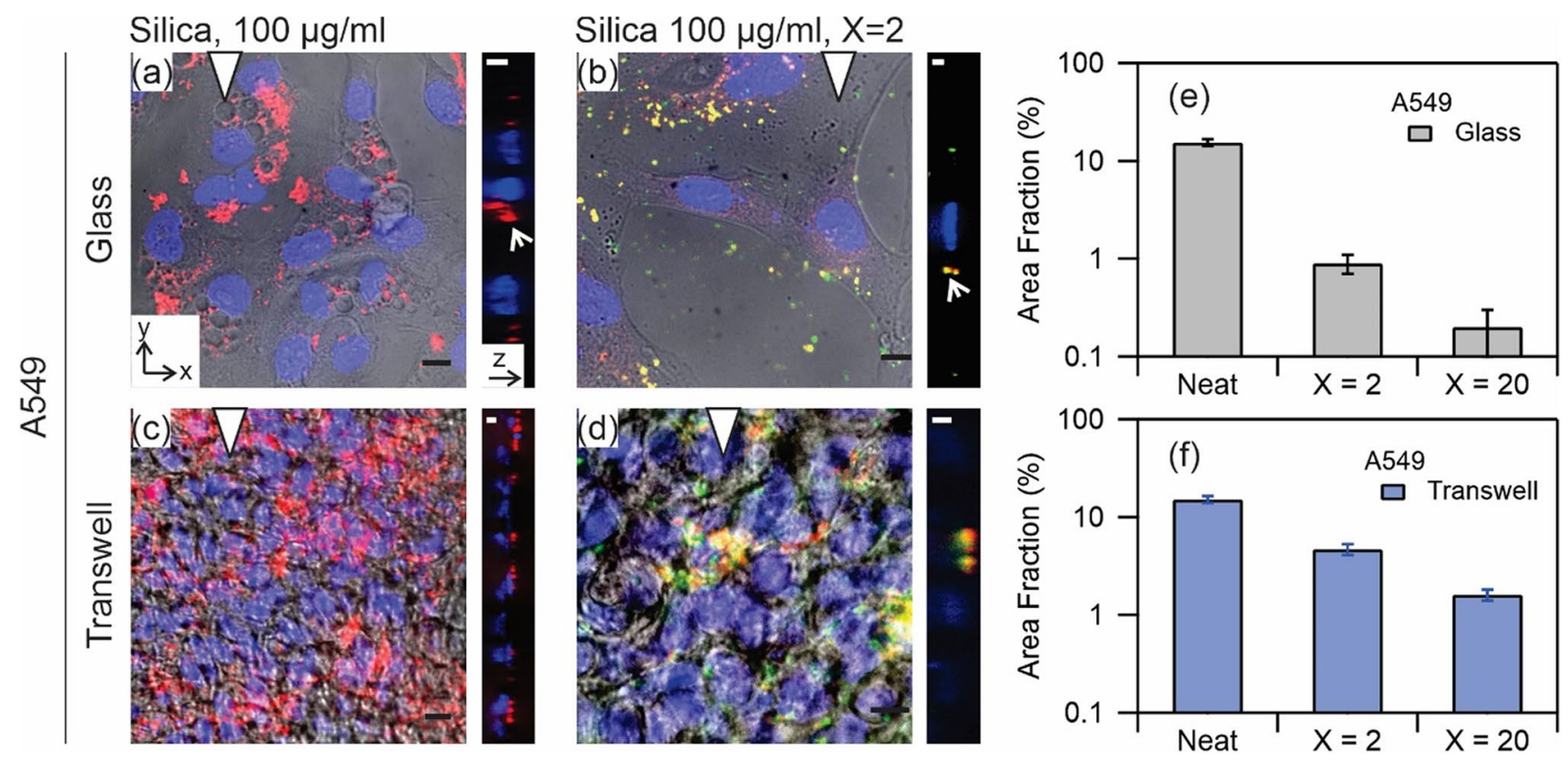

Figure 7. Confocal microscopy images of A549 exposure to silica nanoparticles at $100 \mu \mathrm{g} \mathrm{ml} \mathrm{l}^{-1}$ (a,c) and silica at $100 \mu \mathrm{g} \mathrm{ml}^{-1}$ mixed with Curosurf at $200 \mu \mathrm{g} \mathrm{ml}^{-1}, \mathrm{X}=2(\mathbf{b}, \mathbf{d})$ on glass $(\mathbf{a}, \mathbf{b})$ and on transwell $(\mathbf{c}, \mathbf{d})$. The $\mathrm{X}-\mathrm{y}$ plane images are merges of phase contrast and red, green and blue confocal stacks. The colors are respectively from Cy3-tagged nanoparticles, PKH67-tagged Curosurf and DAPI-tagged nuclei. The presented y-z plane images are merges of red, green and blue confocal stacks, left is bottom and right is top. The triangle positions the $y-z$ plane. Scale bar $10 \mu \mathrm{m}(\mathrm{x}-\mathrm{y})$, and $5 \mu \mathrm{m}(\mathrm{y}-\mathrm{z})$. (e,f) Semi-quantitative analysis of area fraction of nanoparticles per individual cells for three exposure conditions, namely neat silica nanoparticles, and nanoparticles mixed with Curosurf at $\mathrm{X}=2$ and $\mathrm{X}=20$.

Silica, $100 \mu \mathrm{g} / \mathrm{ml}$

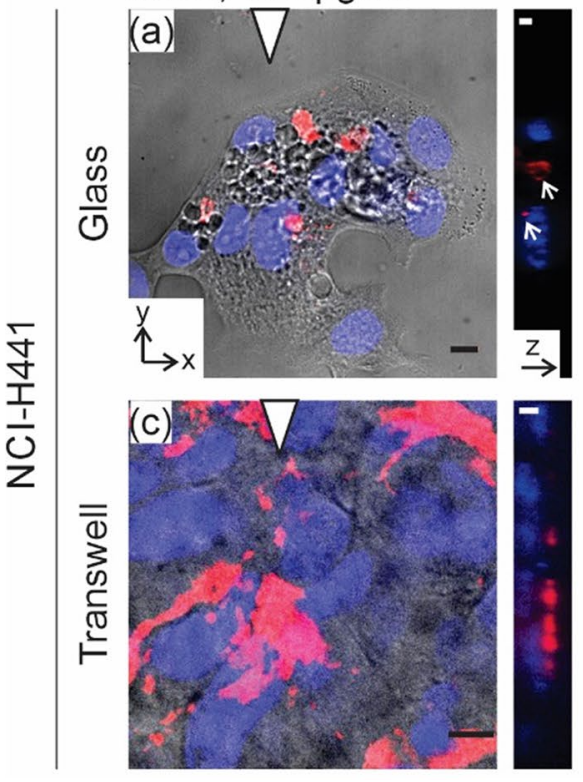

Silica $100 \mu \mathrm{g} / \mathrm{ml}, \mathrm{X}=2$
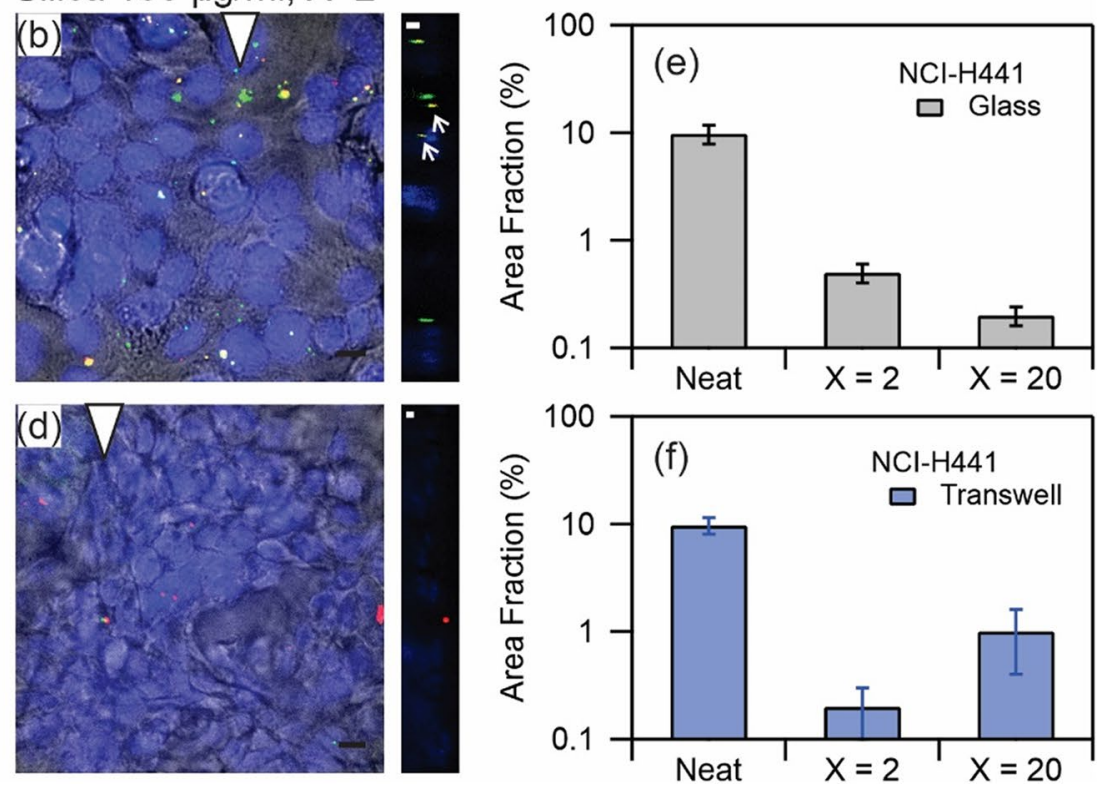

Figure 8. Confocal microscopy images of NCI-H441 exposure to silica nanoparticles at $100 \mu \mathrm{g} \mathrm{ml}^{-1}(\mathbf{a}, \mathbf{c})$ and silica at $100 \mu \mathrm{g} \mathrm{ml}^{-1}$ mixed with Curosurf at $200 \mu \mathrm{g} \mathrm{ml} \mathrm{l}^{-1}, \mathrm{X}=2(\mathbf{b}, \mathbf{d})$ on glass $(\mathbf{a}, \mathbf{b})$ and on transwell $(\mathbf{c}, \mathbf{d})$. The $x-y$ plane images are merges of phase contrast and red, green and blue confocal stacks. The colors are respectively from Cy3-tagged nanoparticles, PKH67-tagged Curosurf and DAPI-tagged nuclei. The presented $\mathrm{y}-\mathrm{z}$ plane images are merges of red, green and blue confocal stacks, left is bottom and right is top. The triangle positions the $y-z$ plane. Scale bar $10 \mu \mathrm{m}(\mathrm{x}-\mathrm{y})$, and $5 \mu \mathrm{m}(\mathrm{y}-\mathrm{z}) .(\mathbf{e}, \mathbf{f})$ Semi-quantitative analysis of area fraction of nanoparticles per individual cells for three exposure conditions, namely neat silica nanoparticles, and nanoparticles mixed with Curosurf at $\mathrm{X}=2$ and $\mathrm{X}=20$. 
and dispersion of nanoparticles and Curosurf at $\mathrm{X}=2$ (Fig. 8b,d). The area fraction is estimated in Fig. 8e,f. Several observations are consistent with A549. The $\mathrm{x}-\mathrm{y}$ plane image of Fig. 8a shows formation of vacuoles inside the cells in this exposure condition and agrees with our previous observation of this response in A549 ${ }^{39}$. The comparisons between Fig. 8 a vs. Fig. 8 b and Fig. $8 \mathrm{c}$ vs. Fig. $8 \mathrm{~d}$ show that the number of internalized or surface bound nanoparticles is reduced when surfactant was present. The yellow spots in the merged images in Fig. $8 \mathrm{~b}$ show that the nanoparticles colocalize with pulmonary surfactant lipids. The orthogonal images in Fig. 8a,b show the aggregates at the level of the nuclei while similar images in Fig. 8c,d show that these aggregates are accumulated in the upper parts and above the nuclei. Semi-quantification in terms of area fraction for individual cells confirms a notable reduction in the area by the surfactant. These results further show the protective role of pulmonary surfactant fluid against silica nanoparticles in NCI-H441.

\section{Discussion}

Our group recently showed that nanoparticles with positive surface charges interact strongly with pulmonary surfactant via electrostatic forces ${ }^{26,29,38}$, and it was speculated that these effects may modulate nanoparticle interactions with cells. In a previous work, we focused our attention on SLB-coated silica nanoparticles ${ }^{39}$. The SLBs were found to significantly reduce cellular internalization of nanoparticles by A549 on glass (S10). Without SLBs, the nanoparticles were found to enter the cells via a non-endocytosis pathway; evident from the absence of vesicles surrounding the internalized nanoparticles or nanoparticle aggregates. Moreover, at the port of entry to the cells, the membrane was damaged. These effects were found to be absent on exposure to SLB-coated nanoparticles clearly manifesting the effect of surfactant SLB on cell protection ${ }^{39}$. The current study investigates the protective role of surfactant in an attempt to mimic the in vivo exposure condition more closely. Thereby, silica nanoparticles and Curosurf were mixed without sonication. We observed with TEM that the vesicular structures in Curosurf are maintained, and that nanoparticles may be internalized inside vesicles and multivesicular structures. Formation of these assemblies, in addition to adhesion of lipid fragments to nanoparticles, are expected to modulate nanoparticle-cell interactions. A549 and NCI-H441 were then investigated cultured on glass and on transwell; the latter substrate was used to stablish ALI and to induce tight junction which is a characteristic of epithelial cells. Indeed, NCI-H441's tight junction proteins were found to be uniformly distributed around the cytoplasm and a high TEER was obtained with this cell line (Figs. 3 and 4). A549 was devoid of these characteristics. Nevertheless, we presented the results of cellular uptake with both cell lines as A549 is a common model that is largely investigated in the past literature. Our previous work was also performed with A549 which allowed cross-checking the outcomes of the current and the previous study. In the tests, the mass of nanoparticles was $200 \mu \mathrm{g}$ for exposure on coverslip and $50 \mu \mathrm{g}$ for exposure on transwell. Correspondingly, the surface concentration of nanoparticles was $20.8 \mu \mathrm{g} \mathrm{cm}^{-2}$ on coverslip and $44.6 \mu \mathrm{g} \mathrm{cm}^{-2}$ on transwell. While the exposed mass is in agreement with the estimated daily lung burden previously discussed, the surface concentration is an overestimation. In fact, recapitulating the large surface area of alveolar region $\left(70 \mathrm{~m}^{2}\right)^{5}$ is not possible in vitro, and further lowering the concentration of nanoparticles may prone them to be undetectable ${ }^{29}$. Thereby our results present a high nanoparticle burden scenario and the effect of surfactant in alleviating such extreme condition. A summary of the exposure conditions is provided in Table 1. A complete overview of the preparation and exposure concentrations is provided in the S3 \& S4. Quantification of nanoparticle uptake using fluorescence microscopy revealed that pulmonary surfactant inhibits the uptake by A549 and NCI-H441 on coverslip and on transwell (Figs. 5 and 6). Particularly, a reduction by one to two orders of magnitude is obtained on exposure to nanoparticle-Curosurf dispersion at $\mathrm{X}=2$ comparing to neat nanoparticles. A further increase in the concentration of Curosurf (condition $\mathrm{X}=20$ ) did not notably reduce the amount of uptake any further. In accordance with DLS measurements, at $\mathrm{X}=2$ and higher, all nanoparticles are readily "complexed" with Curosurf vesicles. A mixing ratio of $X=2$ is apparently sufficient to modify the interactions with the cells and further increase in the $\mathrm{X}$ value is therefore not significant. Confocal microscopy corroborated this result by showing the colocalization of nanoparticles and lipids at $\mathrm{X}=2$. Quantification of area fraction of nanoparticles per individual cells was in agreement with the results from fluorescence microscopy.

We comment on the effect of proteins. We note that the concentration of proteins in Curosurf is minute (S2), and that SP-B and SP-C are membrane proteins. In addition, Curosurf is devoid of the hydrosoluble proteins SP-A and SP-D. For this reason, the protein corona formation is not expected with Curosurf. It may be present however with native surfactant. In the present study, we conclude that the main effect comes from the formation of aggregates with the lipids.

We also comment on the effect of sedimentation on our observations. In particular, the presence of surfactant may change the sedimentation profile of the nanoparticles. It is evident from the results of DLS (S8) that the sizes of the (smaller) aggregates are in the range of a few microns. We suspect that the silica-Curosurf aggregates have a density that is close to that of the vesicles, whereas the density of the nanoparticle aggregates is closer to the density of the silica. This difference may then lead to dissimilar sedimentation profiles between the exposure conditions with and without the surfactant. This difference may have an impact on the effective nanoparticle dose submitted to the cells.

In comparison between the two cell lines, A549 is found to uptake more nanoparticles than NCI-H441. For example, on transwell, only $2 \%$ of the particles are uptaken by NCI-H441. This amount is 3-11\% for A549. Thereby, cells with tight junctions on transwell are "better protected". This finding may be related with the different cellular processes of these cells in interaction with nanoparticles. These differences are indicative of the importance of using relevant alveolar cell models (e.g. NCI-H441 vs. A549) for in vitro investigations, although common models such as A549 may provide useful information on large scale effects. 


\section{Conclusion}

The primary role of pulmonary surfactant is to lower and regulate the air-liquid surface tension in order to facilitate alveolar tissue dynamics during breathing. Its role as a defense mechanism against inhaled nanoparticles is still unknown. We show that pulmonary surfactant inhibits the uptake of positively charged silica nanoparticles in two models of alveolar epithelial cells, namely A549 and NCI-H441. Reductions by up to two orders of magnitude is obtained from analysis of fluorescence signal. Investigation of confocal stacks shows that the nanoparticles are colocalized with surfactant lipids revealing the direct effect of the latter in cellular uptake in accordance with TEM observations of nanoparticle-surfactant interactions. NCI-H441 is a better model for these investigations which is associated with its formation of tight junctions and a high transepithelial resistance when cultured in ALI on transwell. This cell line was also found to uptake less nanoparticles when compared to A549 showing that alveolar cells may even be better protected in vivo. Our findings show the importance of surfactant inclusion in in vitro recreation of alveolar epithelium in inhalation toxicology and therapy investigations.

Received: 19 June 2020; Accepted: 20 October 2020

Published online: 10 November 2020

\section{References}

1. Lelieveld, J., Evans, J. S., Fnais, M., Giannadaki, D. \& Pozzer, A. The contribution of outdoor air pollution sources to premature mortality on a global scale. Nature 525, 367-371 (2015).

2. Weagle, C. L. et al. Global sources of fine particulate matter: interpretation of PM2.5 chemical composition observed by SPARTAN using a global chemical transport model. Environ. Sci. Technol. 52, 11670-11681 (2018).

3. de Donkelaar, A., Martin, R. V., Brauer, M. \& Boys, B. L. Use of satellite observations for long-term exposure assessment of global concentrations of fine particulate matter. Environ. Health Perspect. 123, 135-143 (2015).

4. Hofmann, W. Modelling inhaled particle deposition in the human lung-a review. J. Aerosol Sci. 42, 693-724 (2011).

5. Notter, R. H. Lung Surfactant: Basic Science and Clinical Applications (CRC Press, Boca Raton, 2000).

6. Oberdörster, G., Ferin, J., Gelein, R., Soderholm, S. C. \& Finkelstein, J. Role of the alveolar macrophage in lung injury: studies with ultrafine particles. Environ. Health Perspect. 97, 193-199 (1992).

7. Oberdorster, G. et al. Extrapulmonary translocation of ultrafine carbon particles following whole-body inhalation exposure of rats. J. Toxicol. Environ. Health. A 65, 1531-1543 (2002).

8. Geiser, M. et al. Ultrafine particles cross cellular membranes by nonphagocytic mechanisms in lungs and in cultured cells. Environ. Health Perspect. 113, 1555-1560 (2005).

9. Kreyling, W. G. et al. Size dependence of the translocation of inhaled iridium and carbon nanoparticle aggregates from the lung of rats to the blood and secondary target organs. Inhal. Toxicol. 21, 55-60 (2009).

10. Mercer, R. R. et al. Pulmonary fibrotic response to aspiration of multi-walled carbon nanotubes. Part. Fibre Toxicol. 8, 21 (2011).

11. Semmler-Behnke, M. et al. Efficient elimination of inhaled nanoparticles from the alveolar region: evidence for interstitial uptake and subsequent reentrainment onto airways epithelium. Environ. Health Perspect. 115, 728-733 (2007).

12. Kawasaki, H. A review of the fate of inhaled alpha-quartz in the lungs of rats. Inhal. Toxicol. 31, 25-34 (2019).

13. 13Puisney, C., Baeza-Squiban, A. \& Boland, S. in Cellular and Molecular Toxicology of Nanoparticles Advances in Experimental Medicine and Biology (eds Q. Saquib, M. Faisal, A. A. AlKhedhairy, \& A. A. Alatar) 21-36 (Springer, Berlin, 2018).

14. Lipka, J. et al. Biodistribution of PEG-modified gold nanoparticles following intratracheal instillation and intravenous injection. Biomaterials 31, 6574-6581 (2010).

15. Nie, Z. H. et al. Self-assembly of metal-polymer analogues of amphiphilic triblock copolymers. Nat. Mater. 6, 609-614 (2007).

16. Schmitz, G. \& Muller, G. Structure and function of lamellar bodies, lipid-protein complexes involved in storage and secretion of cellular lipids. J. Lipid Res. 32, 1539-1570 (1991).

17. Parra, E. \& Perez-Gil, J. Composition, structure and mechanical properties define performance of pulmonary surfactant membranes and films. Chem. Phys. Lipids 185, 153-175 (2015).

18. Pérez-Gil, J. Structure of pulmonary surfactant membranes and films: The role of proteins and lipid-protein interactions. Biochem. Biophys. Acta. 1778, 1676-1695 (2008).

19. Morrow, P. E. Possible mechanisms to explain dust overloading of the lungs. Fundam. Appl. Toxicol. 10, 369-384 (1988).

20. Takenaka, S. et al. Efficient internalization and intracellular translocation of inhaled gold nanoparticles in rat alveolar macrophages. Nanomedicine 7, 855-865 (2012).

21. Ruge, C. A. et al. The interplay of lung surfactant proteins and lipids assimilates the macrophage clearance of nanoparticles. $P L o S$ ONE 7, 40775 (2012).

22. Hidalgo, A., Cruz, A. \& Perez-Gil, J. Pulmonary surfactant and nanocarriers: Toxicity versus combined nanomedical applications. Biochim. Biophys. Acta 1859, 1740-1748 (2017).

23. Geiser, M. et al. The role of macrophages in the clearance of inhaled ultrafine titanium dioxide particles. Am. J. Respir. Cell Mol. Biol. 38, 371-376 (2008).

24. Mornet, S., Lambert, O., Duguet, E. \& Brisson, A. The Formation of Supported Lipid Bilayers on Silica Nanoparticles Revealed by Cryoelectron Microscopy. Nano Lett. 5, 281-285 (2005).

25. Le Bihan, O. et al. Cryo-electron tomography of nanoparticle transmigration into liposome. J. Struct. Biol. 168, 419-425 (2009).

26. Mousseau, F. \& Berret, J. F. The role of surface charge in the interaction of nanoparticles with model pulmonary surfactants. Soft Matter 14, 5764-5774 (2018).

27. Mousseau, F., Le Borgne, R., Seyrek, E. \& Berret, J. F. Biophysicochemical Interaction of a Clinical Pulmonary Surfactant with Nanoalumina. Langmuir 31, 7346-7354 (2015).

28. Schleh, C. et al. The effect of titanium dioxide nanoparticles on pulmonary surfactant function and ultrastructure. Respir. Res. 10, 1-11 (2009).

29. Thai, L. P. A., Mousseau, F., Oikonomou, E. K., Radiom, M. \& Berret, J. F. Effect of Nanoparticles on the Bulk Shear Viscosity of a Lung Surfactant Fluid. ACS Nano 14, 466-475 (2020)

30. Vranic, S. et al. Internalization of $\mathrm{SiO} 2$ nanoparticles by alveolar macrophages and lung epithelial cells and its modulation by the lung surfactant substitute Curosurf. Environ. Sci. Pollut. Res. 20, 2761-2770 (2013).

31. Lynn, D. B., Kevin, B., Jo, D., Stefaan, C. D. S. \& Koen, R. The influence of natural pulmonary surfactant on the efficacy of siRNAloaded dextran nanogels. Nanomedicine 8, 1625-1638 (2013).

32. De Backer, L. et al. Bio-inspired pulmonary surfactant-modified nanogels: A promising siRNA delivery system. J. Control. Release 206, 177-186 (2015).

33. Sweeney, S. et al. Silver nanowire interactions with primary human alveolar type-II epithelial cell secretions: contrasting bioreactivity with human alveolar type-I and type-II epithelial cells. Nanoscale 7, 10398-10409 (2015). 
34. Napierska, D., Thomassen, L. C., Lison, D., Martens, J. A. \& Hoet, P. H. The nanosilica hazard: another variable entity. Part. Fibre Toxicol. 7, 39 (2010).

35. 35Goncalves, M. C. Sol-gel Silica Nanoparticles in Medicine: A Natural Choice. Design, Synthesis and Products. Molecules (Basel, Switzerland) 23 (2018).

36. Pavan, C. et al. The puzzling issue of silica toxicity: are silanols bridging the gaps between surface states and pathogenicity?. Part. Fibre Toxicol. 16, 10 (2019).

37. Kurtz-Chalot, A. et al. Adsorption at cell surface and cellular uptake of silica nanoparticles with different surface chemical functionalizations: impact on cytotoxicity. J. Nanopart. Res. 16, 2738 (2014).

38. Mousseau, F. et al. Revealing the pulmonary surfactant corona on silica nanoparticles by cryo-transmission electron microscopy. Nanoscale Advances 2, 642-647 (2020).

39. Mousseau, F. et al. Supported pulmonary surfactant bilayers on silica nanoparticles: formulation, stability and impact on lung epithelial cells. Nanoscale 9, 14967-14978 (2017).

40. Mousseau, F., Berret, J.-F. \& Oikonomou, E. K. Design and Applications of a Fluorescent Labeling Technique for Lipid and Surfactant Preformed Vesicles. ACS Omega 4, 10485-10493 (2019).

41. Kielgast, F. et al. Glucocorticoids Regulate Tight Junction Permeability of Lung Epithelia by Modulating Claudin 8. Am. J. Respir. Cell Mol. Biol. 54, 707-717 (2016).

42. Greenberg, A. K. et al. Glucocorticoids inhibit lung cancer cell growth through both the extracellular signal-related kinase pathway and cell cycle regulators. Am. J. Respir. Cell Mol. Biol. 27, 320-328 (2002).

43. Reinhardt, N., Adumeau, L., Lambert, O., Ravaine, S. \& Mornet, S. Quaternary ammonium groups exposed at the surface of silica nanoparticles suitable for DNA complexation in the presence of cationic lipids. J. Phys. Chem. B 119, 6401-6411 (2015).

44. Helfrich, W. Elastic properties of lipid bilayers: theory and possible experiments. Z. Naturforsch 28C, 693-703 (1973).

45. Jacob, A. M. \& Gaver, D. P. 3rd. Atelectrauma disrupts pulmonary epithelial barrier integrity and alters the distribution of tight junction proteins ZO-1 and claudin 4. J Appl Physiol 113, 1377-1387 (2012).

46. Kuhn, D. A. et al. Different endocytotic uptake mechanisms for nanoparticles in epithelial cells and macrophages. Beilstein J. Nanotech. 5, 1625-1636 (2014).

47. Kasper, J. et al. Interactions of silica nanoparticles with lung epithelial cells and the association to flotillins. Arch Toxicol 87, 1053-1065 (2013).

\section{Acknowledgements}

We thank S. Mornet from Institut de Chimie de la Matière Condenseé de Bordeaux, Université Bordeaux, for synthesis of aminated silica nanoparticle. We thank M. Mokhtari from Hospital Kremlin-Bicefre, Val-de-Marne, France for the gift of Curosurf. We thank C. Puisney and F. Mousseau for viability assay data, TEM images of Curosurf, and DLS data. Agence Nationale de la Recherche (ANR) and Commissariat à l'Investissement d'Avenir (CGI) are acknowledged for financial support of this work through Labex Science and Engineering for Advanced Materials and devices (SEAM) ANR 11 LABX 086, ANR 11 IDEX 0502 . We acknowledge ImagoSeine facility, Jacques Monod Institute, Paris, France, and France BioImaging infrastructure supported by the French National Research Agency (ANR-10-INSB-04, Investments for the future). This research was supported in part by the Agence Nationale de la Recherche under the contract ANR-13-BS08-0015 (PANORAMA), ANR-12-CHEX-0011 (PULMONANO), ANR-15-CE18-0024-01 (ICONS), ANR-17-CE09-0017 (AlveolusMimics) and by Solvay.

\section{Author contributions}

M.R., O.B., A.B.-S. and J.-F.B. designed the experiments. M.R., M.S., O.B. and E.O. performed the measurements. M.R., M.S. and J.-F.B. analyzed the data. M.R. and J.-F.B. wrote the main manuscript text. All authors reviewed the manuscript.

\section{Competing interests}

The authors declare no competing interests.

\section{Additional information}

Supplementary information is available for this paper at https://doi.org/10.1038/s41598-020-76332-7.

Correspondence and requests for materials should be addressed to M.R. or J.-F.B.

Reprints and permissions information is available at www.nature.com/reprints.

Publisher's note Springer Nature remains neutral with regard to jurisdictional claims in published maps and institutional affiliations.

Open Access This article is licensed under a Creative Commons Attribution 4.0 International License, which permits use, sharing, adaptation, distribution and reproduction in any medium or format, as long as you give appropriate credit to the original author(s) and the source, provide a link to the Creative Commons licence, and indicate if changes were made. The images or other third party material in this article are included in the article's Creative Commons licence, unless indicated otherwise in a credit line to the material. If material is not included in the article's Creative Commons licence and your intended use is not permitted by statutory regulation or exceeds the permitted use, you will need to obtain permission directly from the copyright holder. To view a copy of this licence, visit http://creativecommons.org/licenses/by/4.0/.

(C) The Author(s) 2020 